\title{
Current status and comparison of national health insurance systems for advanced radiation technologies in Korea and Japan
}

\author{
Seung Jae Huh ${ }^{1}$, Tetsuo Nishimura ${ }^{2}$, Won Park ${ }^{3}$, Hiroshi Onishi ${ }^{4}$, Yong Chan Ahn $^{3}$, Katsumasa Nakamura ${ }^{5}$ \\ ${ }^{1}$ Department of Healthcare Review and Assessment, Health Insurance Review and Assessment Service, Wonju, Korea \\ ${ }^{2}$ Radiation and Proton Therapy Center, Shizuoka Cancer Center Hospital, Shizuoka, Japan \\ ${ }^{3}$ Department of Radiation Oncology, Samsung Medical Center, Sungkyunkwan University School of Medicine, Seoul, Korea \\ ${ }^{4}$ Department of Radiology, University of Yamanashi, Yamanashi, Japan \\ ${ }^{5}$ Department of Radiation Oncology, Hamamatsu University School of Medicine, Hamamatsu, Japan
}

Received: September 14, 2020

Revised: September 24, 2020

Accepted: September 25, 2020

Correspondence:

Seung Jae Huh

Healthcare Review and Assessment

Committee, Health Insurance Review

and Assessment Service, 304

Hyoryeongno, Seocho-gu, Seoul

06720, Korea.

Tel: +82-2-3410-2616,

E-mail: sjhuh5201@gmail.com

ORCID:

https://orcid.org/0000-0002-3635-8253
Purpose: This study aimed to compare the current status of the national health insurance system (HIS) for advanced radiation technologies in Korea and Japan.Materials and methods: The data of the two nations were compared according to the 2019 guidelines on the application and methods of medical care benefit from the Ministry of Health and Welfare of Korea and the 2020 medical fee points list set by the Ministry of Health, Labor and Welfare of Japan.

Results: Both countries have adopted the social insurance system and the general payment system which is fee-for-service for radiotherapy. However, for proton and carbon ion therapy, the Japanese system has adopted a bundled payment system. Copayment for radiotherapy is $5 \%$ in Korea and $30 \%$ (7-69 years old) in Japan, with a ceiling system. A noticeable difference is that additional charges for hypofractionation, tele-radiotherapy planning for an emergency, tumor motion-tracking, purchase price of an isotope, and image-guided radiotherapy are allowed for reimbursement in the Japanese system. There are some differences regarding the indication, qualification standards, and facility standards for intensity-modulated radiation therapy, stereotactic body radiation therapy, and proton therapy.

Conclusion: Patterns of cancer incidence, use of radiotherapy and infrastructure, and national HIS are very similar between Korea and Japan. However, there are some differences in health insurance management systems for advanced radiation technologies.

Keywords: National health insurance, Intensity-modulated radiation therapy, Stereotactic body radiation therapy, Proton therapy, Korea, Japan

\section{Introduction}

Patterns of cancer incidence and the role of radiotherapy in cancer treatment are very similar between Korea and Japan [1,2]. While $45 \%$ to $55 \%$ of patients with cancer have access to a well-developed radiotherapy infrastructure in the Western countries, in Korea and Japan, $25 \%$ to $30 \%$ of cancer patients are treated with radio- therapy [3-5]. However, there are some differences and similarities in radiotherapy infrastructure and organization patterns between Korea and Japan. Radiotherapy infrastructure showed fragmentation in both nations with a mixed pattern of capital centralization and fragmentation in non-capital areas in Korea, while in Japan, it showed uniform regional distribution [6-8].

Characteristics of both nations' universal health insurance sys-

Copyright (C) 2020 The Korean Society for Radiation Oncology

This is an Open Access article distributed under the terms of the Creative Commons Attribution Non-Commercial License (http://creativecommons.org/licenses/by-nc/4.0/) which permits unrestricted non-commercial use, distribution, and reproduction in any medium, provided the original work is properly cited. 
tem (HIS) are: (1) covering all citizens with social insurance, (2) easy access to medical institutions, and (3) high-quality medical services with low costs and have reached the world's highest level of life expectancy and met the healthcare standards $[9,10]$. However, there are some differences regarding the indication, qualification standards, and facility standards for reimbursement for advanced radiation technologies [11-13].

This study aimed to compare the characteristics and patterns of the HIS for advanced radiation technologies between Korea and Japan by focusing on technologies such as intensity-modulated radiation therapy (IMRT), stereotactic body radiation therapy (SBRT), and particle therapy.

\section{Materials and Methods}

We compared characteristics, patterns of the HIS, specific indications, and facility qualification for advanced radiation technologies between Korea and Japan, focusing on IMRT, SBRT, intracavitary radiotherapy (ICR), proton, and carbon ion therapy. Furthermore, we compared both nations' data according to the 2019 guidelines on the application and methods of medical care benefit from the Ministry of Health and Welfare of Korea and the 2020 medical fee points list set by the Ministry of Health, Labor and Welfare of Japan [11-13]. As the cost of insurance treatment between the two countries varies greatly due to social and economic differences, simple comparison of treatment fee was excluded from this study.

\section{Results}

In Korea and Japan, healthcare service payment in radiotherapy is mainly based on a fee-for-service system. Both the Japanese health insurance system (JHIS) and the Korean health insurance system (KHIS) require the insured and dependents who receive healthcare services to pay copayment that is a part of total healthcare expenses. In KHIS, the copayment for cancer patients is 5\% for all. Meanwhile, copayments in JHIS differ according to age and income status: 10\% for 75 years or older (active income earner, 30\%), 20\% for 70 to 74 years (active income earner, 30\%), 30\% for 7 to 69 years, and 20\% for 6 years or less, respectively. Patients (18 years or younger) with specific chronic pediatric diseases including cancer can be supported according to this income. For pediatric radiotherapy, additional treatment costs ranging from $20 \%$ to $80 \%$ are recognized depending on age in both systems (Table 1). Both have a copayment ceiling to adequately protect patients from catastrophic healthcare expenditures.

The maximum permissible radiotherapy sites and radiotherapy planning for reimbursement during a course of treatment are two in JHIS and three in KHIS, respectively. In JHIS, unlike in KHIS, additional charge for hypofractionation, tumor motion tracking, and IGRT are allowed. Recently, in JHIS, tele-radiotherapy planning for emergency treatment by other institutions has been allowed if there is a lack of suitable manpower (Table 2).

JHIS covers the cost of IMRT for only localized solid malignant tumors, while KHIS covers for metastatic lesions as well. In JHIS, the minimum conditions of IMRT using multi-leaf collimators are defined as follows: (1) more than three portals, (2) more than three intensity-modulated beams per portal, and (3) inverse planning. In JHIS, IMRT is reimbursed when the following personnel are present: (1) two full-time radiation oncologists and a radiotherapy technician, each with more than 5 years of radiotherapy experience and (2) an individual responsible solely for precision control of the radiotherapy devices, irradiation plan verification, and assistance with the irradiation plan (e.g., a radiotherapist or other technician). In KHIS, there are no specific qualifications and facility standards. In both systems, healthcare service payment in IMRT is mainly based on a fee-for-service system that consists of the cost of plan-

Table 1. General comparison of national health insurance system in cancer patients between Japan and Korea

\begin{tabular}{lll}
\hline & \multicolumn{1}{c}{ Japan } & \multicolumn{1}{c}{ Korea } \\
\hline General payment system & Fee for service in general ${ }^{a)}$ & Fee for service \\
Copayment & $\geq 75 \mathrm{yr}: 10 \%$ (active income earner: $30 \%)$ & $5 \%$ of total treatment cost for registered cancer patients \\
& $70-74 \mathrm{yr}: 20 \%$ (active income earner: $30 \%)$ & \\
& $7-69 \mathrm{yr}: 30 \%$ & \\
& $\leq 6 \mathrm{yr}: 20 \%$ & Yes \\
& Yes & $\leq 1 \mathrm{yr}: 50 \%$ \\
Copayment ceiling system & Neonate: $80 \%$ & $1-6 \mathrm{yr}: 30 \%$ \\
Additional charge for pediatric radiotherapy & \\
& $\leq 3 \mathrm{yr}($ excluding neonate): $50 \%$ & \\
\hline & $3-5 \mathrm{yr}: 30 \%$ & \\
\hline
\end{tabular}

${ }^{a}$ Bundle payment for proton and carbon ion therapy. 
Table 2. General comparison of national health insurance system for RT in cancer patients between Japan and Korea

\begin{tabular}{|c|c|c|}
\hline & Japan & Korea \\
\hline Daily examination fee for outpatient RT & Yes & No \\
\hline $\begin{array}{l}\text { Maximum allowable RT sites for reimbursement } \\
\text { during a course of treatment }\end{array}$ & $\begin{array}{l}\text { Two (50\% price for } 2 \text { nd site except IMRT, SBRT, and } \\
\text { particle therapy) }\end{array}$ & Three (100\% price for all site) \\
\hline Maximum allowable RTP during a course of treatment & Twice (Same price except SBRT and particle therapy) & Three times ( $50 \%$ fee from 2 nd plan) \\
\hline Additional charge for hypo fractionation & Yes for prostate and breast cancer RT & No \\
\hline Remote RTP for emergency & Yes & No \\
\hline Extra charge for tumor motion tracking & Yes & No \\
\hline Extra charge for IGRT & Yes & No \\
\hline
\end{tabular}

RT, radiotherapy; RTP, radiotherapy planning; IGRT, image-guided radiation therapy; IMRT, intensity-modulated radiation therapy; SBRT, stereotactic body radiation therapy.

Table 3. Comparison of national health insurance system for IMRT utilization, and facility qualification between Japan and Korea

\begin{tabular}{|c|c|c|}
\hline & Japan & Korea \\
\hline \multirow[t]{3}{*}{ Indication } & Limited solid malignant tumor ${ }^{a}$ & $\begin{array}{l}\text { Solid tumor (primary, metastatic cancer, and } \\
\text { CNS benign tumors) }\end{array}$ \\
\hline & & Re-RT \\
\hline & & Boost therapy \\
\hline \multirow[t]{2}{*}{$\begin{array}{l}\text { Three most common cancers using IMRT and } \\
\text { utilization }\end{array}$} & $\begin{array}{l}\text { In 2014-2018 survey, (1) prostate cancer, (2) head } \\
\text { and neck cancer, (3) CNS tumor }\end{array}$ & $\begin{array}{l}\text { In } 2018 \text { survey, (1) breast cancer, (2) lung } \\
\text { cancer, (3) prostate cancer }\end{array}$ \\
\hline & 15\% in 2017 survey & $23 \%$ in 2016 survey \\
\hline Qualification standards & $\begin{array}{l}\text { Two or more full-time radiation oncologists, at } \\
\text { least one of them with RT experience for } 5 \text { years } \\
\text { or more }\end{array}$ & Not specified \\
\hline \multirow[t]{5}{*}{ Facility standards } & Linear accelerator & Not specified \\
\hline & Planning CT & \\
\hline & Inverse RT planning system & \\
\hline & $\begin{array}{l}\text { Equipment restricting patient movement and of } \\
\text { organs within the body }\end{array}$ & \\
\hline & $\begin{array}{l}\text { Micro-ionization chamber or semiconductor } \\
\text { dosimeter (including diamond dosimeter) and } \\
\text { water phantom or equivalent solid phantom }\end{array}$ & \\
\hline
\end{tabular}

IMRT, intensity-modulated radiation therapy; CNS, central nervous system; RT, radiotherapy; CT, computed tomography.

a) Metastatic lesion is not permitted.

ning, treatment, and immobilization device. In JHIS, additional costs for hypofractionated IMRT (daily dose 250 cGy or more) for prostate cancer, and in IGRT costs for tumor tracking are allowed (Tables 3, 4).

ICR treatment costs consist of the cost of each part of JHIS, but in KHIS, the cost for the entire treatment is ceilinged. In Korea, the total cost for 5 or more fractionations of ICR is the same. However, in JHIS, unlike in KHIS, extra-charge for image-guided planning and the purchase price of the isotope have been added to the cost of the treatment as one-time for the entire course of the high dose rate ICR (Table 5). Specific indications for SBRT covered by both countries are relatively similar regarding the organs. Oligo-metastases for SBRT is defined by five sites or less in both systems. General indication for tumor size for SBRT is defined by $5 \mathrm{~cm}$ or less in JHIS. The details have been presented in Table 6.
JHIS for proton and carbon ion therapy has been adopted as a bundle or package price. Proton therapy for pediatric solid tumor is covered by the HIS in both countries. However, there are some differences in specific indications and facility qualifications for proton therapy in both countries. In JHIS, indication for proton and carbon ion therapy covered by health insurance are defined as follows: (1) pediatric solid tumor; (2) localized inoperable bone and soft tissue sarcoma; (3) head and neck cancers (except squamous cell cancer of oral cavity, larynx, and pharynx); and (4) prostate cancer. However, KHIS has adopted a wider range of indications (Table 7). If the treatment decision for proton or carbon ion therapy is made through a multidisciplinary tumor board, then the additional treatment fee is recognized in JHIS. 
Table 4. Details of IMRT related specific treatment cost between Japan and Korea

\begin{tabular}{lcc}
\hline & Japan & \multicolumn{1}{c}{ Korea } \\
\hline IMRT planning fee & Yes & Yes \\
IMRT treatment fee & Yes & Yes \\
Full time radiation oncologist extra charge & Yes & No \\
Daily examination fee for out patient & Yes \\
Immobilization device & Yes \\
Hypofractionation charge for daily dose 250 cGy or more & Yes (for prostate cancer only) \\
Additional cost for IGRT for tumor tracking according to body surface, bony structure, and & Yes \\
\hline
\end{tabular}

IMRT, intensity-modulated radiation therapy; IGRT, image-guided radiation therapy.

Table 5. Comparison of national health insurance system for ICR for cervical cancer between Japan and Korea in 2020

\begin{tabular}{lll}
\hline & \multicolumn{1}{c}{ Japan } & \multicolumn{1}{c}{ Korea $^{\text {a) }}$} \\
\hline ICR cost & JPY 120,000 per fraction & KRW 1,783,652 for whole course \\
Maximum allowable RTP during a course of treatment & Four times including EBRT plan in entire course & Twice for ICR plan \\
& $100 \%$ fee for all plans & $50 \%$ fee for 2nd plan \\
Additional charge for image guided brachytherapy & Yes (JPY 12,000 for whole course) & No \\
Cost of isotope use (iridium) & Yes (purchase price / 50 $\times$ JPY 10) & No \\
\hline
\end{tabular}

ICR, intracavitary radiotherapy; RTP, radiotherapy planning; EBRT, external beam radiotherapy.

${ }^{a)}$ Korean treatment fee is based on basic and 30\% additional charge for tertiary hospital.

Table 6. Specific indications for SBRT covered by national health insurance system

\begin{tabular}{ll}
\hline Japan $^{\text {a) }}$ & \\
\hline Primary lung cancer: $\leq 5 \mathrm{~cm}$ without other organ metastases & Korea \\
Metastatic lung, liver tumor: $\leq 3$ metastases without other organ metastases & Lung cancer (stage 1 or medically inoperable) \\
Primary hepatic cancer: $\leq 5 \mathrm{~cm}$ without other organ metastases & Hepatobiliary and pancreas cancer \\
Primary renal cell cancer: $\leq 5 \mathrm{~cm}$ without other organ metastases & Urologic cancer (kidney, prostate, bladder, etc.) \\
Prostate cancer: without metastases & Bone tumor \\
Pancreatic cancer: without metastases & Sarcoma \\
Arteriovenous malformation of spinal cord & Breast cancer (post conserving surgery) \\
Spinal metastasis: $\leq 5 \mathrm{~cm}$ & Cervical cancer (as a substitute for intracavitary therapy) \\
Oligo-metastases: $\leq 5 \mathrm{sites}$ and $\leq 5 \mathrm{~cm}$ & Head and neck cancer \\
& Regional lymph node metastases or recurrence \\
& Re-irradiation therapy \\
& Boost radiotherapy \\
\hline
\end{tabular}

SBRT, stereotactic body radiation therapy.

${ }^{\text {a) }}$ Only once in case of multiple courses of SBRT to same site within several months.

\section{Discussion and Conclusion}

Both Japan and Korea have adopted the social insurance system which enables rapid and easy access to medical care with low cost for all citizens and meets the world's highest level of life expectancy and healthcare standards. In countries adopting a tax-financed system, it is pointed out that citizens cannot choose a medical institution and waiting time to access medical care is generally long. For example, in the UK, general physicians (registered family physi- cians) are in charge of primary medical care. However, it is a problem as the waiting time is too long $[9,10]$. Fee-for-service payments are calculated by multiplying the price per score and resource-based relative value scores (RBRVS) based on the amount of work and resources such as manpower, facilities, equipment, and risks of medical treatments and the fee charged for each activity. The Ministry of Health and Welfare of Korea determines RBRVS. In Japan, the medical service fees grading table is used to evaluate costs by grading individual technologies and services, determined 
Table 7. Specific indications for proton and carbon ion therapy covered by national health insurance system of both countries and facility qualification

\begin{tabular}{|c|c|c|}
\hline & Japan (proton and carbon ion therapy) & Korea (proton therapy) \\
\hline \multirow[t]{7}{*}{ Indication } & Pediatric solid tumor & Pediatric cancer \\
\hline & \multirow{4}{*}{$\begin{array}{l}\text { Localized inoperable bone and soft tissue } \\
\text { sarcoma } \\
\text { Head and neck cancers (except squamous cell } \\
\text { cancer of oral cavity, larynx, and pharynx) }\end{array}$} & Re-RT \\
\hline & & Brain, skull base, and spinal tumors \\
\hline & & Head and neck cancer including orbit \\
\hline & & Thorax tumor (lung, esophagus, and mediastinum \\
\hline & \multirow[t]{2}{*}{ Prostate cancer } & except breast cancer) \\
\hline & & $\begin{array}{l}\text { Abdominal tumors (hepatobiliary, pancreas, and } \\
\text { retroperitoneum) }\end{array}$ \\
\hline Payment system & Bundle payment & Fee for service \\
\hline $\begin{array}{l}\text { Incentive for tumor board for decision for } \\
\text { particle treatment }\end{array}$ & Yes & No \\
\hline $\begin{array}{l}\text { Particle facility qualification standards for radia- } \\
\text { tion oncologist }\end{array}$ & $\begin{array}{l}\text { More than } 2 \text { radiation oncologists, one of them } \\
\text { more than } 2 \text { and } 10 \text { years' experiences in } \\
\text { particle and RT, respectively. }\end{array}$ & Not specified \\
\hline
\end{tabular}

$\mathrm{RT}$, radiotherapy.

by the Ministry of Health, Labor, and Welfare $[11,12]$.

For the hypofractionated three-dimensional whole breast radiation (daily 2.5 Gy or more) instead of a conventional dose (46 to 50 Gy in 23 to 25 fractions), additional treatment cost is permitted in JHIS based on the randomized clinical results, which can reduce the number of hospital visits and the load on radiotherapy institutes [14]. In JHIS, tele-radiotherapy planning for emergency treatment is allowed if there is a lack of suitable manpower. This tele-radiotherapy planning for an emergency by another institution can be used to help with emergency treatment at poorly staffed treatment facilities.

The utilization rate of IMRT is steadily increasing. In Japan, it was 15\% in 2017, while in Korea it was 23\% in 2016 [15,16] (Table 3). There are some differences regarding the indication, qualifications, and facility standards for IMRT between two countries. JHIS covers the cost of IMRT for only localized solid malignant tumors, while KHIS covers for metastatic lesions as well. Oligo-metastasis may be considered as an indication for IMRT in KHIS. According to the Japanese Society for Radiation Oncology database report of 2018, IMRT was mostly used to treat prostate, head and neck, and central nervous system tumors in Japan [17]. However, in Korea, IMRT was most commonly used to treat breast, lung, and prostate cancers in 2018 [13].

JHIS adopted stricter indications for proton and carbon ion therapy (Table 7). Although the American Society for Radiation Oncology did not recommend proton therapy for prostate cancer outside of a prospective clinical trial, it is covered by JHIS [18]. However, in JHIS, the cost of proton therapy for prostate cancer is cheaper than other treatments and is set to be similar to the total cost of IMRT. If the treatment decision for proton or carbon ion therapy is made through a multi-disciplinary tumor board the additional treatment fee is recognized in Japan.

In conclusion, patterns of cancer incidence, infrastructure, and HIS are very similar between Korea and Japan. However, there is a considerable difference regarding the additional charges for hypofractionation, tumor motion tracking, and purchase price of an isotope among others. Furthermore, there are some differences regarding the indication, qualification standards, and facility standards for IMRT, SBRT, and proton therapy.

\section{Conflict of Interest}

No potential conflict of interest relevant to this article was reported.

\section{References}

1. National Cancer Center Cancer Control Information Center. Projected cancer incidence in 2019 [Internet]. Tokyo, Japan: National Cancer Center Cancer Control Information Center; 2020 [cited 2020 Sep 25]. Available from: https://ganjoho.jp/ reg_stat/statistics/stat/summary.html.

2. National Cancer Information Center. Cancer statistics [Internet]. Goyang, Korea: National Cancer Information Center; 2019 [cited 2020 Sep 25]. Available from: https://www.cancer.go.kr/lay1/ S1T639C642/contents.do.

3. Delaney G, Jacob S, Featherstone C, Barton M. The role of radiotherapy in cancer treatment: estimating optimal utilization from a review of evidence-based clinical guidelines. Cancer 2005;104: 1129-37.

4. Seo YS, Kim MS, Kang JK, et al. The clinical utilization of radiation therapy in Korea between 2011 and 2015. Cancer Res Treat 


\section{8:50:345-55.}

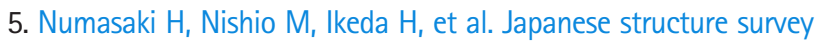
of radiation oncology in 2009 with special reference to designated cancer care hospitals. Int J Clin Oncol 2013;18:775-83.

6. Nakamura K, Konishi K, Komatsu T, Sasaki T, Shikama N. Patterns of radiotherapy infrastructure in Japan and in other countries with well-developed radiotherapy infrastructures. Jpn J Clin Oncol 2018;48:476-9.

7. Huh SJ, Nishimura T, Park W, Nakamura K. Comparison of radiotherapy infrastructure between Korea and Japan. Jpn J Clin Oncol 2019;49:1024-8.

8. Huh SJ; Korean Society of Therapeutic Radiology and Oncology (KOSTRO). Current status of the infrastructure and characteristics of radiation oncology in Korea. Jpn J Clin Oncol 2007;37:623-7.

9. Ministry of Health, Labor and Welfare of Japan. Overview of Medical Service Regime in Japan [Internet]. Tokyo, Japan: Ministry of Health, Labor and Welfare; c2020 [cited 2020 Sep 25]. Available from: https://www.mhlw.go.jp/bunya/iryouhoken/iryouhoken01/dl/01_eng.pdf.

10. National Health Insurance Service. NIH program: National Health Insurance System of Korea [Internet]. Wonju, Korea: National Health Insurance Service; c2020 [cited 2020 Sep 25]. Available from: https://www.nhis.or.kr/static/html/wbd/g/a/wbdga0405. html.

11. Health Insurance Review and Assessment Service. 2019 Guidelines on the application and methods of medical care benefit [Internet]. Wonju, Korea: Health Insurance Review and Assessment
Service; 2019 [cited 2020 Sep 25]. Available from: https://www. hira.or.kr/sViewer/index.do?ebookSn $=548$.

12. The medical fee points list: radiotherapy Tokyo, Japan: Igakutushinsya Co. Ltd.; 2020.

13. Huh SJ, Park W, Choi DH. Recent trends in intensity-modulated radiation therapy use in Korea. Radiat Oncol J 2019;37:249-53.

14. Nozaki M, Kagami Y, Shibata T, et al. A primary analysis of a multicenter, prospective, single-arm, confirmatory trial of hypofractionated whole breast irradiation after breast-conserving surgery in Japan: JCOG0906. Jpn J Clin Oncol 2019;49:57-62.

15. Japanese Society for Radiation Oncology. 2017 Simple structure survey [Internet]. Tokyo, Japan: Japanese Society for Radiation Oncology; 2018 [cited 2020 Sep 25]. Available from: https:// www.jastro.or.jp/medicalpersonnel/data_center/cat6/cat1/post6.html.

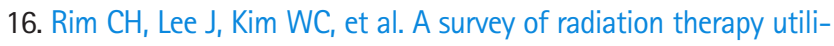
zation in Korea from 2010 to 2016: focusing on use of intensity-modulated radiation therapy. J Korean Med Sci 2018;33:e67.

17. Japanese Society for Radiation Oncology. JASTRO Radiotherapy Cases National Registration Project (JROD) 2018 survey report [Internet]. Tokyo, Japan: Japanese Society for Radiation Oncology; 2019 [cited 2020 Sep 25]. Available from: https://www.jastro. or.jp/medicalpersonnel/data_center/cat6/jrod/2018.html.

18. Hahn C, Kavanagh B, Bhatnagar A, et al. Choosing wisely: the American Society for Radiation Oncology's top 5 list. Pract Radiat Oncol 2014;4:349-55. 